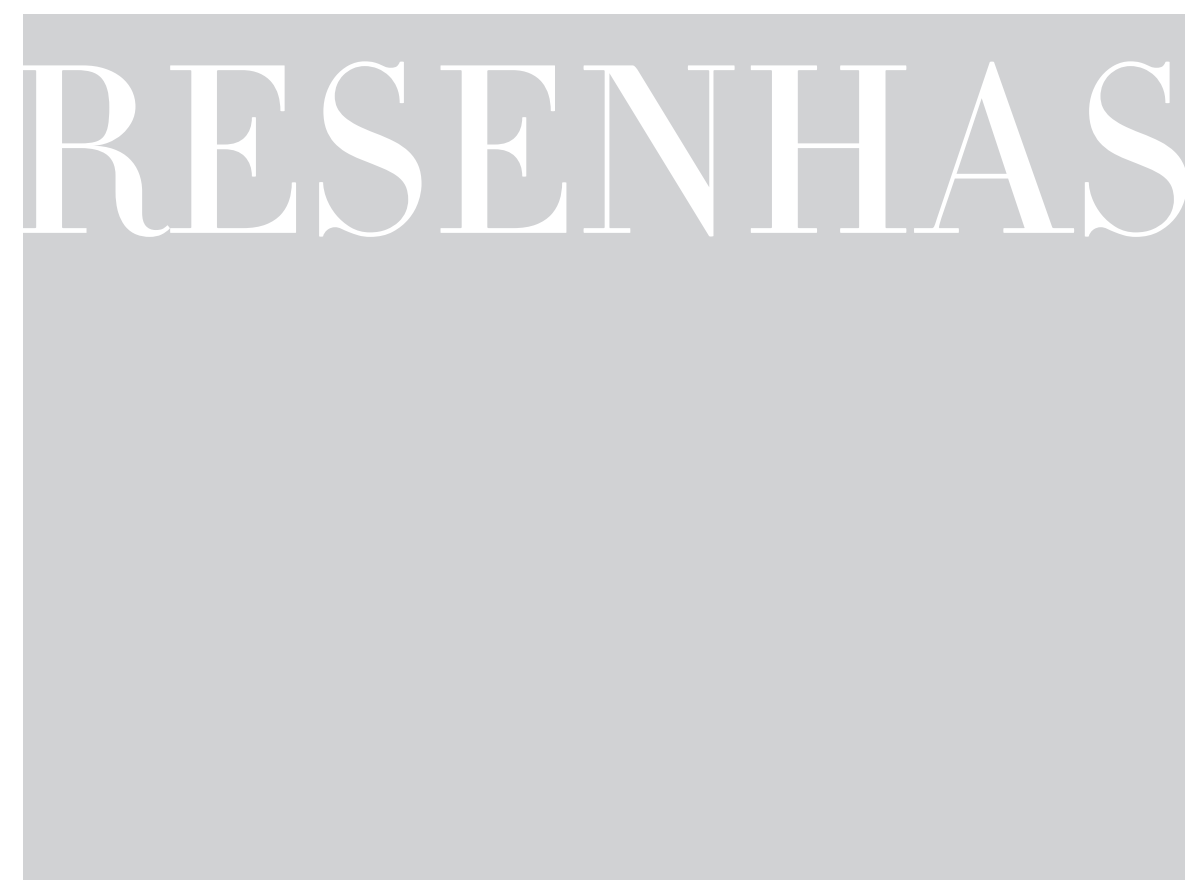

\title{
MÍDIA-EDUCAÇÃO E ESCOLA: MEIOS DIGITAIS E CULTURA POPULAR
}

http://dx.doi.org/10.1590/198053143463

HOBBS, Renee; MOORE, David C. Discovering media literacy: teaching digital media and popular culture in elementary school. Thousand Oaks: Corwin, 2013. 256p.

As mídias e as tecnologias digitais perpassam todo o corpo da sociedade contemporânea, estando presentes na vida de adultos, idosos, jovens e crianças. As culturas juvenil e infantil, ${ }^{1}$ em especial, vêm sofrendo alterações dinâmicas, influenciadas por essas mídias. Crianças e jovens, inseridos na instituição escola, vêm se tornando uma preocupação para a educação, assim como a relação entre esses grupos sociais e as tecnologias digitais. Logo, desenvolve-se um novo campo no espectro educacional: a mídia-educação, que surge na tentativa de estudar as relações das mídias e tecnologias digitais com o processo educacional.

Os jovens e as crianças acabam recebendo uma atenção especial juvenil" e "cultura infantil" fazem alusão aos jovens e às crianças enquanto atores sociais, agentes na construção e reconstrução de sua cultura própria enquanto um grupo social. Para mais informações sobre juventude, ver Margulis (2001), Arroyo (2014), Weller (2014). Para mais informações sobre infância, ver Corsaro (2011)

\section{da} pelo fato de serem os principais sujeitos inseridos na escola. O campo ainda encontra muitas teorias e práticas fragmentadas, o que é explicitado pela diversidade de nomes que fazem referência a tais estudos, como, por exemplo, mídia-educação, letramento midiático, educomunicação, todos em uma corrente similar de pensamento, porém com ligeiras divergências.

Nesse contexto, Renee Hobbs e David Cooper Moore desenvolveram a obra Discovering media literacy: teaching digital media and popular culture in elementary school, que se situa no campo da media literacy education. ${ }^{2}$ Hobbs é uma das principais autoridades em mídia-educação 
nos Estados Unidos, sendo também fundadora e diretora da Harrington School of Communication and Media, na Universidade de Rhode Island, na qual coordena o Laboratório de Mídia-educação. Cooper Moore é diretor do programa Powerful Voices for Kids, principal ação ligada ao laboratório de Mídia Educação na Harrington School of Communication and Media.

O livro, que apresenta diversas experiências vividas no Powerful Voices for Kids, um programa de extensão desenvolvido entre a Universidade de Rhode Island e diversas escolas do mesmo estado, está organizado em cinco partes, somando nove capítulos.

Na primeira parte, "Why digital and media literacy matters", dois capítulos discorrem, em linguagem agradável ao leitor e próxima à realidade do professor, sobre a importância em conceber crianças e jovens como produtores de cultura e não apenas como receptores, ideia também desenvolvida por David Buckingham (2003), que afirma a necessidade de estudar a relação entre infância e mídias, como um processo fluido, histórico e socialmente construído. Além disso, os autores comentam aspectos teóricos da integração das mídias ao contexto escolar e abordam a relação de amor e ódio, vivida pela maioria dos professores, com a cultura popular e de massa. A primeira parte do livro é finalizada com a apresentação de um quadro teórico, desenvolvido pelos autores, com o objetivo de interpretar as motivações dos professores que trabalham com mídias digitais, apresentando diferentes perfis traçados a partir da observação de monitores no programa. ${ }^{3}$

A segunda parte do livro, "Work with intermediate students", composta por quatro capítulos, trata do trabalho com crianças de 9 a 11 anos. No primeiro, é enfatizada a necessidade de conectar a sala de aula à cultura das crianças e jovens que frequentam a escola. Inspirados, em parte, pelo trabalho de Marshall McLuhan e sua visão da influência do contexto cultural na formação e na educação das crianças, os autores sugerem que a escola seria apenas um fragmento desse processo, devendo toda a cidade funcionar como uma sala de aula. Por meio do relato de experiências reais, eles abordam tópicos da cultura infantil e de jovens, suas realidades, os locais onde vivem, as mídias que consomem, e ainda debatem estratégias para que esses alunos critiquem e construam um sentido a tudo isso.

Ao longo dos próximos três capítulos, sempre com um exemplo de experiência real, Hobbs e Moore discutem a importância de um ensino crítico, desenvolvido principalmente nas indagações das crianças, pela valorização das perguntas e na criação de um ambiente estimulante à formulação de dúvidas e questões. Aliadas a essa busca pela criticidade, são comentadas algumas atividades desenvolvidas no programa, por monitores, nas quais as crianças desenvolvem e criam mídias audiovisuais, digitais e até mesmo desenhos. Nesse ponto, surgem dois aspectos que, segundo os autores, são essenciais para o desenvolvimento de um pensamento crítico: a criatividade e a percepção do contexto social. Os

O termo literacy pode ser traduzido como letramento, se aproximando do termo letramento midiático, porém seu significado para o português brasileiro estaria mais próximo de alfabetização. Devido a problemas como esse, há muita divergência nas traduções de diferentes autores. 3 Os autores convidam todos interessados a responderem um quiz na tentativa de traçar seu perfil motivacional em < www. powerfulvoicesforkids.com>. 
autores afirmam que uma intervenção ou projeto, em mídia-educação, deve, ao mesmo tempo, estimular a criatividade dos alunos e abranger uma temática da realidade social vivida pela criança ou jovem. Dessa forma, o objetivo de um ensino crítico poderá ser atingido.

Em "Work with primary children in grades K-2", a terceira parte do livro, são abordadas, em dois capítulos, as possibilidades de trabalho com crianças pequenas de 5 a 7 anos de idade. Segundo os autores esse é um trabalho possível, mas que requer muita atenção, pois a pouca diferença de idades pode fazer muita diferença na compreensão das mídias. Hobbs e Moore apresentam uma discussão sobre a relevância no uso de tecnologias com crianças pequenas, mostrando posicionamentos divergentes de professores regentes. Indaga-se se a dinâmica da infância teria o mesmo ritmo que a das mídias digitais, ou seja, essas mídias estariam fazendo sentido para as crianças? Os autores não deixam bem definida sua resposta a tal indagação, porém, se posicionam a favor da mídia-educação com os pequenos, deixando entender que acreditam nessa proposta.

São apresentadas ao leitor, por meio de relatos de experiências, no mesmo padrão dos capítulos anteriores, estratégias com crianças na educação infantil e nos primeiros anos do ensino fundamental. Segundo os autores, devem ser dados pequenos passos, visando desenvolver noções visuais, como o enquadramento, a tela, ou também de personagens, como, por exemplo, a percepção de uma personagem enquanto representação e não realidade. Além disso, podem ser desenvolvidas noções de autoria e audiência. Tudo isso realizado sempre de forma lúdica, criativa e com objetos conhecidos pelas crianças, seus desenhos favoritos, histórias infantis, programas de televisão, jogos, etc.

Na quarta parte, “Approaches to teacher education”, os autores mudam o foco dos alunos para os professores, no decorrer de um capítulo voltado para a importância da formação de profissionais da educação. São apresentadas ao leitor as principais iniciativas do programa, como o curso de verão, em que diversos profissionais, de diferentes áreas, experimentam práticas em mídia-educação, ou também os seminários de curta duração. Porém, o capítulo se aprofunda nas parcerias entre universidades e escolas, em que monitores do laboratório, um deles o próprio David Cooper Moore, coordenados por Renee Hobbs, criam, em conjunto com professores das escolas, intervenções em sala de aula. Por meio de diversos encontros e reuniões, os monitores e a coordenadora do projeto discutem e preparam materiais e estratégias que em seguida são levados, em conjunto, para os professores interessados, na tentativa de sensibilizar a prática desses profissionais com a mídia-educação.

A quinta e última parte do livro, "Extras”, traz ricos recursos a serem utilizados pelo leitor, supostamente um professor, em sua sala de aula. São eles: um quadro de objetivos para o trabalho com crianças pequenas; um glossário de termos a ser desenvolvido com as crianças; 
um glossário de conceitos em mídia-educação; e um breve informativo sobre os instrutores do programa citados no decorrer do livro.

A obra é um excelente introdutor do campo para professores, sendo claramente pensada para os profissionais da educação de forma prática e concisa. O livro tem um importante aspecto pragmático, deixando nítida a tentativa de seduzir o leitor ao trabalho com mídias digitais. Durante toda a extensão do livro, os temas e ideias são apresentados com exemplos muito bem descritos; múltiplos relatos enriquecem e exemplificam a riqueza e as possibilidades encontradas em um trabalho crítico sobre, com e para as mídias. Ao decorrer de cada capítulo também aparecem variados quadros apresentando dicas, sites, dinâmicas, fontes de pesquisa e de aprofundamento acerca da temática enfatizada. Além disso, um fator relevante do livro refere-se aos exemplos de plano de aula expostos ao final de cada capítulo, todos desenhados em um mesmo formato, resultados de pesquisas desenvolvidas no programa Powerful Voices for Kids.

Apesar de seu rico potencial prático, a obra não aprofunda as diversas discussões teóricas do campo. Esse, claramente, não era o objetivo dos autores, que visaram à disseminação de suas experiências práticas. Na realidade, a obra apresenta um pragmatismo complementar ao livro publicado em 2010 e 2011 por Renee, que, por sua vez, traz uma discussão teórica sobre mídias e educação. ${ }^{4}$

Percebe-se ainda um extremo otimismo dos autores, que fazem a prática parecer muito fácil e fluida, comentando apenas rapidamente as reais dificuldades e o empenho necessário na aplicação de suas intervenções, como a bagunça em sala de aula e o afastamento natural entre o professor adulto e as culturas infantil e jovem.

Apesar de sua forte influência no campo das mídias nos Estados Unidos, as publicações de Hobbs e Cooper Moore ainda não repercutem tanto no Brasil. Tocantins (2012) utiliza as teorias de Hobbs em sua dissertação de mestrado, sendo uma das primeiras autoras, no contexto nacional, a empregar sua fundamentação teórica sobre as mídias na educação.

Por fim, o livro é um excelente guia e introdutor da mídia-educação para profissionais da educação, independentemente de sua área de formação. O leitor brasileiro deve apenas atentar para as diferenças entre o nosso contexto e o estadunidense. Recomendamos sua leitura a todos interessados no campo, seja da mídia-educação, letramento midiático, ou educomunicação, justamente por mostrar uma variedade de materiais e estratégias muito útil para o trabalho em sala de aula.

\section{REFERÊNCIAS}


BUCKINGHAM, David. Media-education: literacy, learning and contemporary culture. Cambridge: Polity Press, 2003.

CORSARO, William. Sociologia da infância. Porto Alegre: Artmed, 2011.

HOBBS, Renee. Digital and media literacy: a plan of action. Washington, D.C.: The Aspen Institute, November 2010.

Digital and media literacy: connecting culture and classroom. California: Corwin, 2011.

MARGULIS, Mario. Juventud: una aproximación conceptual. In: BURAK, S. D. (Org.). Adolescencia y juventud em América Latina. Costa Rica: LUR, 2001. p. 41-56.

TOCANTINS, Geusiane. Apropriações de tecnologias da informação e comunicação por professores no contexto da educação do corpo na escola. 2012. Dissertação (Mestrado) - Universidade de Brasília, Brasília, 2012.

WELLER, Wivian. Os jovens no ensino médio: projetos de vida e perspectivas de futuro. In: DAYRELL, J.; CARRANO, P.; MAIA, C. L. (Org.). Juventude e ensino médio: sujeitos e currículos em diálogo. Belo Horizonte: UFMG, 2014. p. 135-154.

\section{JOÃO DA SILVEIRA GUIMARÃES}

Mestrando no Programa de Pós-Graduação em Educação Física e integrante do Grupo de Pesquisa sobre Corpo e Educação - Imagem - da Universidade de Brasília - UnB -, Brasília, Distrito Federal, Brasil joaoedf.guimaraes@gmail.com

\section{INGRID DITTRICH WIGGERS}

Professora doutora da Faculdade de Educação Física e coordenadora do Grupo de Pesquisa sobre Corpo e Educação - Imagem - da Universidade de Brasília - UnB -, Brasília, Distrito Federal, Brasil; bolsista sênior de pós-doutorado CNPq/UnB $2014 / 2015$

ingridwiggers@gmail.com

\section{GEUSIANE MIRANDA DE OLIVEIRA TOCANTINS}

Doutoranda no Programa de Pós-Graduação em Educação e integrante do Grupo de Pesquisa sobre Corpo e Educação - Imagem - da Universidade de Brasília - UnB -, Brasília, Distrito Federal, Brasil; professora da Secretaria de Educação do Distrito Federal geusi.nte@gmail.com 